\title{
THE ANTEROLATERAL LIGAMENT OF THE KNEE: EMERGING INTEREST FOR RECONSTRUCTIVE SURGERY
}

\section{Anita Rahul Gune *1, Dhanaji T Wagh ${ }^{2}$, Vasudha R Nikam ${ }^{3}$.}

${ }^{* 1}$ Associate Professor, Dept. of Anatomy, D.Y.Patil Medical College, Kolhapur, Maharashtra, India.

2 Tutor, Dept. of Anatomy, D.Y.Patil Medical College, Kolhapur, Maharashtra, India.

${ }^{3}$ Associate Dean, Professor and HOD, Dept. of Anatomy, D. Y. Patil Medical College, Kolhapur, Maharashtra, India.

\section{ABSTRACT}

Background: The anterolateral ligament (ALL) originates from the lateral epicondyle of the femur and inserts on the tibia in between Gerdy's tubercle (GT) and fibula head (FH). The ALL exists as a ligamentous structure that becomes taut if tibia is rotated $30^{\circ}$ medially. It has been suggested that the ALL of the knee has importance in limiting rotational instability, and reconstruction of the same along with anterior cruciate ligament $(A C L)$ may prevent a continued pivot-shift following surgery. We describe our experience of cadaveric dissection with reference to other published.

Materials and Methods: This study was conducted in Department of Anatomy, D.Y.Patil Medical College, Kolhapur from 2016 to 2018. The ALL was identified in 14 Females and 16 Males cadavers, total 60 knee joints. The ALL tissue was identified with internal rotation of the tibia. Measurements were made using a digital calliper and details of the origin and insertion were recorded.

Results: The ALL was identified had mean dimensions were: length $38.06 \pm 3 \mathrm{~mm}$ on Right side and $37.94 \pm 3 \mathrm{~mm}$ on Left side, width $4.38 \pm 0.25 \mathrm{~mm}$ on Right side and $4.37 \pm 0.25 \mathrm{~mm}$ on Left side, thickness $0.9 \pm 0.02 \mathrm{~mm}$ on Right side and $0.9 \pm 0.02 \mathrm{~mm}$ on Left side. The femoral origin Posterior and Proximal (PP) in 23, Anterior and Distal (AD) in 29 and Femoral Lateral Epicondyle in 8 knee joint. The tibial insertion was a mean $1.79 \pm 0.3 \mathrm{~mm}$ on Right side and $1.82 \pm 0.3 \mathrm{~mm}$ on Left side from Gerdy's tubercle $(\mathrm{GT})$ and $1.28 \pm 0.03 \mathrm{~mm}$ on Right side and $1.25 \pm 0.03 \mathrm{~mm}$ on Left side from the fibula head (FH).

Conclusions: Our results go along the studies describing that the ALL is a capsular thickening and has meniscal attachment. The findings will help surgeon to perform reconstructive surgery and also help them to select the appropriate graft. Further, we feel this ligament should be added in all gross anatomy book so that medical undergraduates are also aware of ALL.

KEY WORDS: Anterolateral Ligament (ALL), Anterior Cruciate Ligament (ACL), Reconstructive surgery.

Address for Correspondence: Dr. Anita Rahul Gune, MS Anatomy, D.G.O (CPS), Associate Professor, Dept. of Anatomy, Dr. D.Y.Patil Medical College, Kolhapur 416006. Maharashtra, India. Phone 0231 2658770, 9922108770, E-Mail: anitargune@gmail.com

Access this Article online

Quick Response code

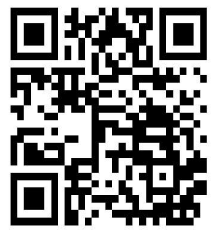

DOI: $10.16965 /$ ijar.2018.194
Journal Information

International Journal of Anatomy and Research

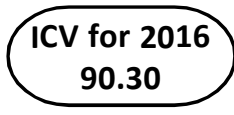

ISSN (E) 2321-4287 | ISSN (P) 2321-8967

https://www.ijmhr.org/ijar.htm

DOI-Prefix: https://dx.doi.org/10.16965/ijar

\section{Article Information}

Received: 21 Mar 2018

Peer Review: 21 Mar 2018

Revised: None
Accepted: 08 May 2018

Published (O): 05 Jun2018

Published (P): 05 Jun 2018

\section{INTRODUCTION}

Paul Segond in 1879 [1] while operating for avulsion fracture, noted a band of fibrous tissue in proximal region of tibia. He described this band to be present at anterolateral region of proximal tibia. This band later in 2012, was named as the anterolateral ligament (ALL) of the knee by Vincent [2]. 
Various studies conducted to enumerate structure which help knee joint to be stabilised. These studies report that Anterior Cruciate ligament $(\mathrm{ACL})$ and Anterolateral ligament (ALL) play a strong role as stabilisers for rotational movements [3]. Different studies correlated injury of $A C L$ to injury to $A L L$ [2-7]. For performing reconstructive surgery on knee joint in cases of injury of $A C L$, it is important to refer biomechinal studies stating that rotational movement primary stabiliser is ACL and secondary stabiliser is ALL. To summarise if $A C L$ is repaired along with $A L L$ results seen in reducing tibial instability will be better [8-10].

This ligament is described by different authors as "pearly band" attached to Segond fracture [1], mid-third (lateral) capsular ligament [11], anterior oblique band of lateral collateral ligament [12].

Understanding of morphology of this ALL was done through anatomical dissection $[2,5,13,14]$ by $\mathrm{H} \& \mathrm{E}$ staining of this fibrous band $[2,5]$, with help of films ( $x$ ray) [15-18]. Usually the study was conducted in association with damage to ACL [19].

Inspite of papers describing ALL, there are some controversy. Some studies report presence of ALL only in $50 \%$ cases [20]. Few mentioned ALL as capsular structure with attachment to lateral meniscus $[2,5]$. Whereas few studies describe ALL as outside capsule structure [13].

Our goal was to identify the structure that appeared to be controlling anterolateral rotation, characterise its dimensions and attachments, and interpret them in the context of previous work.

\section{MATERIALS AND METHODS}

Dissection of sixty cadaveric knee specimens, 14 female and 16 male bodies with no evidence of surgical scars were used for this study. This study was conducted in Department of Anatomy, D.Y.Patil Medical College, and Kolhapur from 2016 to 2018. Both right and left knees with soft tissue proximal and distal to the joint line were dissected. No medical history excluding previous injuries was available.

Gross anatomic dissection was performed, after removal of skin and subcutaneous tissue, the iliotibial band was dissected from the Gerdy's tubercle (GT) from distal to proximal. The lliotibial tract was cut proximal to its insertion and care was taken to elevate this without damaging the deep structures. The attachments of the short and long heads of the biceps femoris muscle were released from the femoral origin and reflected distally, allowing for a visualization of the lateral collateral ligament. The tibia was internally rotated, throughout the dissection, to identify structures under tension. The lateral collateral ligament ( $L C L$ ) was defined (as an easily identifiable structure) and dissection proceeded anteriorly to isolate the tight structure (the ALL) as shown in Figure 1. Further dissection was then performed to demonstrate any attachments to the capsule and lateral meniscus. The presence of the $A C L$ was then determined intra-articularly. Once isolated, the attachments of the ALL were taken in relation to the centre of the fibula head (FH) and GT. The dimensions of the ALL were recorded using a digital calliper (capacity $=150 \mathrm{~mm}$, accuracy $0.01 \mathrm{~mm}$ ).

\section{RESULTS AND DISCUSSION}

Fig. 1: Right Knee Joint.

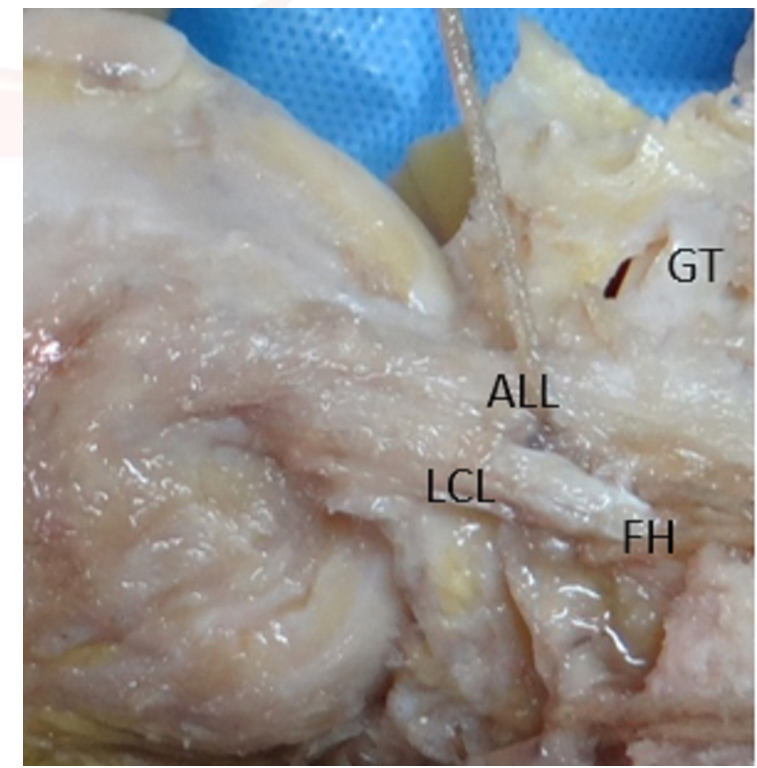

ALL - Anterolateral Ligament, LCL- Lateral Collateral Ligament, GT- Gerdy's Tubercle, FH- Fibula Head

Table 1: Tibial insertion of Anterolateral ligament.

\begin{tabular}{|c|c|c|c|}
\hline \multicolumn{2}{|c|}{$\begin{array}{c}\text { Tibial Insertion from Gerdy's } \\
\text { Tubercle }\end{array}$} & \multicolumn{2}{c|}{ Tibial Insertion from Fibula Head } \\
\hline Right & Left & Right & Left \\
\hline $1.79 \pm 0.3 \mathrm{~mm}$ & $1.82 \pm 0.3 \mathrm{~mm}$ & $1.28 \pm 0.03 \mathrm{~mm}$ & $1.25 \pm 0.03 \mathrm{~mm}$ \\
\hline
\end{tabular}


Table 2: Femoral origin of Anterolateral ligament.

\begin{tabular}{|c|c|}
\hline Femoral Origin & Number \\
\hline Posterior and Proximal (PP) & 23 \\
\hline Anterior and Distal (AD) & 29 \\
\hline Femoral Lateral Epicondyle & 8 \\
\hline
\end{tabular}

Table 3: Dimensions of Anterolateral ligament.

\begin{tabular}{|c|c|c|c|c|c|}
\hline \multicolumn{2}{|c|}{ Length } & \multicolumn{2}{c|}{ Width } & \multicolumn{2}{c|}{ Thickness } \\
\hline Right & Left & Right & Left & Right & Left \\
\hline $38.06 \pm 3 \mathrm{~mm}$ & $37.94 \pm 3 \mathrm{~mm}$ & $4.38 \pm 0.25 \mathrm{~mm}$ & $4.37 \pm 0.25 \mathrm{~mm}$ & $0.9 \pm 0.02 \mathrm{~mm}$ & $0.9 \pm 0.02 \mathrm{~mm}$ \\
\hline
\end{tabular}

The ALL was identified in 14 Females and 16 Males cadavers, total 60 knee joints. We found in our cadaveric study presence of ALL in all 60 specimens of Knee joint, in all of these $A C L$ was also present. With review from previous cadaveric studies our findings correlate with many studies [5,13,14,20,21,22]

Our findings demonstrated capsular thickening at Anterolateral region of Knee joint, which on internal rotation became taut. These mimic the findings by various authors $[2,5,21,22]$.

In our study the Tibial attachment was $1.8 \pm 0.3$ $\mathrm{mm}$ from GT and $1.2 \pm 0.03 \mathrm{~mm}$ from $\mathrm{FH}$ as shown in Table 1. These results makes it obvious that the tibial attachment of ALL was more towards $\mathrm{FH}$.

The femoral origin of ALL in our study as shown in Table 2 were almost same like Caterine et al. We described femoral origin in three groups from centre of femoral lateral epicondyle, Posterior and Proximal to Femoral epicondyle and Anterior and Distal to Femoral epicondyle. All of these femoral attachments in relation to centre of lateral femoral epicondyle exist on same line passing through these structures.

In cases with PP attachment of $L C L$, it was noted that ALL was superficial to the LCL. Similar results are reported by other authors $[13,21]$.

If we compare our study dimensions of ALL to majority of studies, the results are comparable $[5,20,26,27]$. Table 3 shows results of our study, length of $38 \pm 3 \mathrm{~mm}$, a width of $4.37 \pm 0.25 \mathrm{~mm}$ and thickness of average of $0.9 \pm 0.02 \mathrm{~mm}$.

\section{CONCLUSION}

In summary, our study suggest that the ALL represents a capsular thickening at anterolateral region of knee joint. The dimensions of our specimen were same as these group $[5,16,21,22]$. The tibial attachment is found to lie between $\mathrm{GT}$ and the $\mathrm{FH}$, with the femoral origin as described by Caterine et al. [21], was lying around the $\mathrm{LCL}$ attachment to the lateral femoral epicondyle at or PP or AD.

This study has added to the current literature regarding the morphology of the ALL. This is important basic knowledge useful in reconstructive surgery. While reconstruction of $A C L$, to prevent post-operative instability reconstruction of the ALL should be considered. Looking at structure of ALL, it is logical that it plays in restricting abnormal movements of Knee joint. The directions of fibres of ALL and tightening of this structure during internal rotation of the tibia helps us to understand the function of ALL.

Autograft or Allograft used for reconstruction of ALL are from the iliotibial tract, gracilis tendon, and semitendinosus tendon. While reconstructing ALL recreating to the lateral meniscus may be of advantage and also selecting a graft tissue of a similar thickness may prevent complications [23]. During reconstruction surgery the angle of fixation mentioned are different ranging from $60^{\circ}$ to $90^{\circ}$ of flexion to full knee extension [24]. Further, we feel this ligament should be added in all gross anatomy book so $1^{\text {st }}$ year M.B.B.S students are also aware of ALL.

\section{ABBREVIATIONS}

ALL - Anterolateral Ligament

ACL- Anterior Cruciate Ligament

LCL- Lateral Collateral Ligament

GT- Gerdy's Tubercle

FH- Fibula Head

PP- Posterior and Proximal

AD- Anterior and Distal

\section{ACKNOWLEDGEMENTS}

We are really grateful to all cadaveric donors for wilful donated their bodies. We will like to thanks family members of donors as well.

\section{Conflicts of Interests: None}

\section{REFERENCES}

[1]. Caterine S, Litchfield R, Johnson M, Chronik B, Getgood A. A cadaveric study of the anterolateral ligament: re-introducing the lateral capsular ligament. Knee Surgery, Sports Traumatology, Arthroscopy. 2015 Nov 1;23(11):3186-95. 
[2]. Vincent JP, Magnussen RA, Gezmez F, Uguen A, Jacobi M, Weppe F, Al-Saati MF, Lustig S, Demey G, Servien $E$, Neyret $P$. The anterolateral ligament of the human knee: an anatomic and histologic study. Knee Surg Sports Traumatol Arthrosc 2012;20:147-152.doi: 10.1007/s00167-011-1580-3

[3]. Monaco E, Ferretti A, Labianca L, Maestri B, Speranza A, Kelly MJ, D'Arrigo C. Navigated knee kinematics after cutting of the $\mathrm{ACL}$ and its secondary restraint. Knee Surg Sports Trau matol Arthrosc. 2012;20:870877. doi:10.1007/s00167-011-1640-8

[4]. Colombet P. Knee laxity control in revision anterior cruciate ligament reconstruction versus anterior cruciate ligament reconstruction and lateral tenodesis: clinical assessment using computer-assisted navigation. Am J Sports Med 2012;39:1248-1254. doi:10.1177/0363546510395462

[5]. Helito CP, Demange MK, Bonadio MB, Týrico LEP, Gobbi RG, Pecora JR, Camanho GL. Anatomy and histology of the knee anterolateral ligament. Orthop J Sports Med 2013;1:1-5. doi: 10. 1177/2325967113513546

[6]. Trojani C, Beaufils $P$, Burdin G, Bussie're C, Chassaing $V$, Djian P, Dubrana F, Ehkirch FP, Franceschi JP, Hulet $C$, Jouve F, Potel JF, Sbihi A, Neyret $P$, Colombet $P$. Revision ACL reconstruction: influence of a lateral tenodesis. Knee Surg Sports Traumatol Arthrosc 2012; 20:1565-1570. doi:10.1007/s00167-011-1765-9.

[7]. Vadala AP, lorio R, De Carli A, Bonifazi A, lorio C, Gatti A, Rossi C, Ferretti A. An extra-articular procedure improves the clinical outcome in anterior cruciate ligament reconstruction with hamstrings in female athletes. Int Orthop 2013;37:187-192. doi:10.1007/ s00264-012-1571-0

[8]. Edwards DJ, Brown JN, Roberts SN, Paterson RS. Longterm results of anterior cruciate ligament reconstruction using ilio-tibial tract and semitendinosus tendon. Knee 2000;7:87-93.

[9]. Marcacci M, Zaffagnini S, Giordano G, lacono F, Presti ML. Anterior cruciate ligament reconstruction associated with extra-articular tenodesis: a prospective clinical and radiographic evaluation with 10- to 13year follow-up. Am J Sports Med 2009;37:707-714. doi: $10.1177 / 0363546508328114$.

[10]. Pernin J, Verdonk P, Si Selmi TA, Massin P, Neyret P. Long-term follow-up of $\mathbf{2 4 . 5}$ years after intra-articular anterior cruciate ligament reconstruction with lateral extra-articular augmentation. Am J Sports Med 2010;38:1094-1102. doi:10.1177/ 0363546509361018308

[11]. LaPrade RF, Gilbert TJ, Bollom TS, Wentorf F, Chaljub G. The magnetic resonance imaging appearance of individual structures of the posterolateral knee. A prospective study of normal knees and knees with surgically verified grade III injuries. Am J Sports Med 2000;28:191-199.

[12]. Campos JC, Chung CB, Lektrakul N, Pedowitz R, Trudell $D, Y u$ J, Resnick D. Pathogenesis of the Segond fracture: anatomic and MR imaging evidence of the iliotibial tract or anterior oblique band avulsion. Radiology 2001;219:381-386.
[13]. Dodds AL, Halewood C, Gupte CM, Williams A, Amis $A A$. The anterolateral ligament: anatomy, length changes and association with the Segond fracture. Bone Joint J 2014;96:325-331. doi:10.1302/0301620X.96B3.33033

[14]. Vieira EL, Vieira EA, da Silva RT, Berlfein PA, Abdalla RJ, Cohen M. An anatomic study of the iliotibial tract. Arthroscopy 2007;23:269-274. doi:10.1016/ j.arthro.2006.11.019

[15]. Claes S, Bartholomeeusen S, Bellemans J. High prevalence of anterolateral ligament abnormalities in magnetic resonance images of anterior cruciate ligament-injured knees. Acta Orthop Belg 2014;80:4549.

[16]. Helito CP, Helito PV, Costa HP, Bordalo-Rodrigues M, Pecora JR, Camanho GL, Demange MK. MRI evaluation of the anterolateral ligament of the knee: assessment in routine 1.5-T scans. Skeletal Radiol 2014;43:1421-1427. doi: 10.1007/s00256-014-1966-7.

[17]. Helito CP, Demange MK, Bonadio MB, Tirico LE, Gobbi RG, Pecora JR, Camanho GL. Radiological markers for locating the femoral origin and tibial insertion of the knee anterolateral ligament. Am J Sports Med 2014;42:2356-2362. doi: 10.1177/ 0363546514543770.

[18]. Rezansoff AJ, Caterine S, Spencer L, Tran MN, Litchfield RB, Getgood AM. Radiographic landmarks for surgical reconstruction of the anterolateral ligament of the knee. Knee Surgery, Sports Traumatology, Arthroscopy. 2015 Nov 1;23(11):3196-201.

[19]. Claes S, Luyckx T, Vereecke E, Bellemans J. The Segond fracture: a bony injury of the anterolateral ligament of the knee. Arthroscopy. 2014 Nov 1;30(11):1475-82.

[20]. Hughston JC, Andrews JR, Cross MJ, Moschi A. Classification of knee ligament instabilities. Part II. The lateral compartment Bone Joint Surg Am 1976;58:173179.

[21]. Caterine S, Litchfield R, Johnson M, Chronik B, Getgood A. A cadaveric study of the anterolateral ligament: re-introducing the lateral capsular ligament. Knee Surgery, Sports Traumatology, Arthroscopy. 2015 Nov 1;23(11):3186-95.

[22]. laes S, Vereecke E, Maes M, Victor J, Verdonk P, Bellemans J. Anatomy of the anterolateral ligament of the knee. Journal of anatomy. 2013 Oct 1;223(4):3218.

[23]. Jonathan D. Kosy, Ashish Soni, Ramakrishnan Venkatesh, Vipul I. Mandalia. The anterolateral ligament of the knee: unwrapping the enigma. Anatomical study and comparison to previous reports. J Orthopaed Traumatol 2016;17:303-308 DOI 10.1007/ s10195-016-0392-0

[24].Edwards DJ, Brown JN, Roberts SN, Paterson RS. Long term results of anterior cruciate ligament reconstruction using ilio-tibial tract and semitendinosus tendon. Knee 2000;7:87-93.

How to cite this article:

Anita Rahul Gune, Dhanaji T Wagh, Vasudha R Nikam. THE ANTEROLATERAL LIGAMENT OF THE KNEE: EMERGING INTEREST FOR RECONSTRUCTIVE SURGERY. Int J Anat Res 2018;6(2.3):5316-5319. DOI: 10.16965/ijar.2018.194 